\title{
Severe hyponatremia and repeated intestinal resections for intestinal dysmotility mimicking congenital aganglionic megacolon due to delay in the diagnosis of congenital hypothyroidism
}

\author{
Gonul Buyukyilmaz, MD', \\ Demet Baltu, MD², \\ Tutku Soyer, $\mathrm{MD}^{3}$, \\ Murat Tanyıldı, MD', \\ Huseyin Demirbilek, MD ${ }^{1}$
}

${ }^{1}$ Department of Paediatric Endocrinology, Hacettepe University Faculty of Medicine, Ankara, ${ }^{2}$ Department of Paediatrics, Hacettepe University Faculty of Medicine, Ankara, ${ }^{3}$ Department of Paediatric Surgery, Hacettepe University Faculty of Medicine, Ankara, ${ }^{4}$ Department of Paediatric Intensive Care Unit, Hacettepe University Faculty of Medicine, Ankara, Turkey

Received: 25 August, 2016

Revised: 23 October, 2016

Accepted: 7 December, 2016

Address for correspondence:

Huseyin Demirbilek, MD

Department of Paediatric

Endocrinology, Hacettepe University,

Ankara, Turkey

Tel: +903123051124

Fax: +903123121809

E-mail:dr_huseyin@hotmail.com
Congenital hypothyroidism $(\mathrm{CH})$ may present with nonspecific signs and symptoms, though, majority of infants can be asymptomatic. Therefore, understimation and delay in diagnosis may result in severe complications. A 5-month-old female admitted to our clinic with the history of repeated surgical operations due to the diagnosis of congenital aganglionic megacolon. Investigations performed in our clinic revealed the diagnosis of congenital (primary) hypothyroidism due to thyroid agenesis. Histopathologic evaluation of previously resected colon sample revealed normal ganglionic cell included colon. During follow-up she developed severe hyponatremia with a plasma sodium level of $106 \mathrm{mEq} / \mathrm{L}$. Eunatremia was maintained following achievement of euthyroid state. In conclusion, since presenting symptoms can be variable and nonspecific, hypotyhroidism should be kept in mind in the differential diagnosis of patients with persistent abdominal distention mimicking aganglionic megacolon and severe hyponatremia of unknown origin.

Keywords: Congenital hypothyroidism, Hyponatremia, Congenital aganglionic megacolon

\section{Introduction}

Congenital hypothyroidism $(\mathrm{CH})$, the most common preventable cause of mental retardation in children, has an incidence rate between 1 in 2,500 and 1 in 4,000 newborns ${ }^{1)}$. The signs and symptoms of $\mathrm{CH}$ are hoarse cry, feeding difficulty, constipation, abdominal distention, vomiting, puffy (myxedematous) facies, macroglossia, umbilical hernia, large fontanelles, hypotonia, dry skin, hypothermia, prolonged jaundice and lethargy. Most newborns can be asymptomatic, however, most of them become symptomatic within several months after birth. This may cause delay in diagnosis thereby severe mental retardation.

Hyponatremia, is a rare finding of myxedama in adult. It is usually mild and asymptomatic. Although, is extremely rare, severe hyponatraemia (plasma sodium $<120 \mathrm{mmol} / \mathrm{L}$ ), can be lifethreatening. In children, hypotyhroidism associated hyponatremia is further rare with few number of case reports in the literature ${ }^{2-4)}$. The underlying mechanism for hypothroidism induced hyponatraemia is not well known. Impaired renal and cardiovascular functions, disorders in hypothalamus-pituitary-adrenal axis, antidiuretic hormone (ADH) and atrial natriuretic peptide (ANP) release, are suspected underlying mechanisms for development of hyponatremia in hypothyroidism, ${ }^{5,6)}$.

Herein, we report delay in the diagnosis of $\mathrm{CH}$ in a female infant, who developed severe 
hyponatremia and abdominal distention mimicking congenital aganglionic megacolon that required repeated surgeries and releated complications.

\section{Case report}

A 5-month-old female was admitted to our pediatric surgery department with the complaints of abdominal distention and vomiting. She was born after 40 weeks of uneventful gestation to a 26-year-old mother via cesarean section. Her birth weight was 4,200 g. She had developed neonatal jaundice which was prolonged and required phototherapy and phenobarbital therapies. She was readmitted at the age of 1 month with the complaints of vomiting, abdominal distention, and poor feeding. A diagnosis of intestinal dysmotility due to congenital aganglionic megacolon was considered thereby surgical resection and reanastomosis operation performed. After that,

Table 1. Laboratory investigations at the time of admission

\begin{tabular}{lcc}
\hline Variable & Patient's result & Normal ranges \\
\hline $\mathrm{Na}(\mathrm{mEq} / \mathrm{L})$ & 132 & $135-145$ \\
$\mathrm{~K}(\mathrm{mEq} / \mathrm{L})$ & 3.74 & $3.4-4.7$ \\
$\mathrm{Cl}(\mathrm{mEq} / \mathrm{L})$ & 103 & $101-109$ \\
Blood urea nitrogen $(\mathrm{mg} / \mathrm{dL})$ & 5.8 & $5-18$ \\
Creatinine $(\mathrm{mg} / \mathrm{dL})$ & 0.26 & $0.26-0.77$ \\
Glucose $(\mathrm{mg} / \mathrm{dL})$ & 79 & $70-100$ \\
Calcium $(\mathrm{mg} / \mathrm{dL})$ & 8.29 & $8.8-10.8$ \\
Phosphorus $(\mathrm{mg} / \mathrm{dL})$ & 3.01 & $3.3-5.6$ \\
Alkaline phosphatase $(\mathrm{IU} / \mathrm{L})$ & 289 & $93-309$ \\
Uric acid (mg/dL) & 1.57 & $3.5-7.2$ \\
Blood count & & \\
Hemoglobin $(\mathrm{g} / \mathrm{dL})$ & 10.3 & $11-14$ \\
Hct $(\%)$ & 41.4 & $35-45$ \\
White blood cell count $(/ \mu \mathrm{L})$ & $13 \times 10^{3}$ & $5-13 \times 10^{3}$ \\
Platelet count $(/ \mu \mathrm{L})$ & $339 \times 10^{3}$ & $180-400 \times 10^{3}$ \\
Urinalysis & & - \\
Specific gravity & 1.011 & - \\
PH & 6.5 & - \\
Glucose & Negative & - \\
Protein & Negative & \\
\hline
\end{tabular}

she had undergone 6 more operations due to postsurgical complications and persisted symptoms (e.g., repair for leak of the anastomosis, repair for intestinal perforation, colostomy, jejunostomy etc.). On admission to our hospital her weight was $3,800 \mathrm{~g}$ ( $<3$ rd percentile), anterior fontanelle was $3 \mathrm{~cm} \times 3 \mathrm{~cm}$. She had a dried and crumped skin, abdominal distention and severe neuro-developmental delay. Laboratory investigations at the time of admission are presented at Table 1. Abdominal X-ray showed mild intestinal distention. Histopathologic evaluation of previously resected intestinal specimens revealed a normal ganglion cell including colon samples.

At the second day of hospitalization, while she was already on intravenous hypotonic $0.225 \%$ saline $(100 \mathrm{~mL} / \mathrm{kg})$ infusion, she developed a moderate hyponatremia which was corrected using $120 \mathrm{~mL} / \mathrm{kg} 0.45 \%$ saline infusion (Table 2). There was no signs of volume expansion or depletion, vomiting, diarrhea or gastrostomy tube loss. After $0.45 \%$ saline replacement plasma sodium levels rised up to $134 \mathrm{mEq} / \mathrm{L}$ (Fig. 1).

Investigation of thyroid function tests revealed free thyroxine (FT4): $0.4 \mathrm{pmol} / \mathrm{L}$ (7.8-14.4) and thyroid-stimulating hormone (TSH): $>100 \mu \mathrm{IU} / \mathrm{mL}(0.34-5.6)$. Thyroid imaging using $99 \mathrm{mTc}-$ pertechnetate scan and correlative thyroid ultrasonography revealed thyroid agenesis (Fig. 2). A diagnosis of primary hypothyroidism due to thyroid agenesis was considered and L-Thyroxine therapy commenced at a daily dose of $50 \mu \mathrm{g}(12.5$ $\mu \mathrm{g} / \mathrm{kg} /$ day) from the $3 \mathrm{rd}$ hospital day.

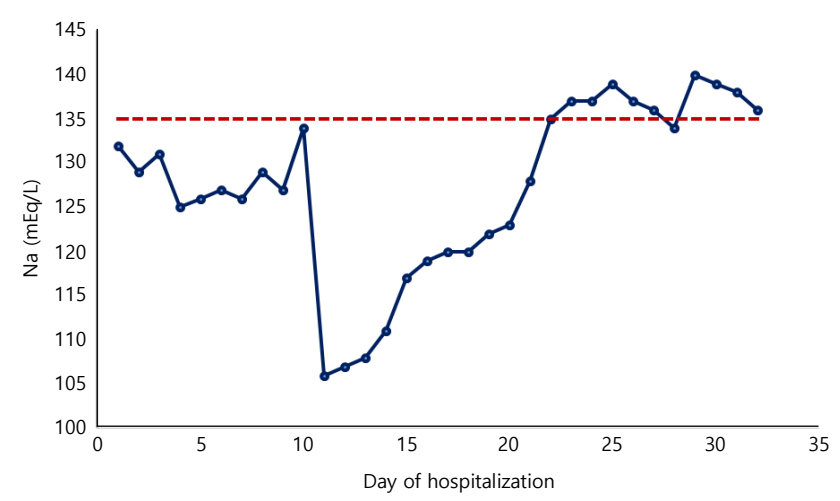

Fig. 1. Plasma sodium levels of patient during follow-up.

Table 2. Presenting and follow up biochemical and hormonal characteristics of patient

\begin{tabular}{|c|c|c|c|c|c|c|c|c|}
\hline Variable & Day 1 & Day 2 & Day 3 & Day 6 & Day 11 & Day 12 & Day 13 & Day 16 \\
\hline Plasma Na (mEq/L) (136-146) & 132 & 125 & 126 & 134 & 106 & 117 & 120 & 136 \\
\hline $\mathrm{K}(\mathrm{mEq} / \mathrm{L})(3.4-4.7)$ & 3.74 & 4.6 & 4.4 & 4.9 & 4.3 & 3.9 & 4.1 & 5.1 \\
\hline $\mathrm{Cl}(\mathrm{mEq} / \mathrm{L})(101-109)$ & 103 & 96 & 91 & 108 & 80 & 93 & 95 & 110 \\
\hline Urine $\mathrm{Na}(\mathrm{mEq} / \mathrm{L})(15-267)$ & - & 119 & - & - & - & - & 147 & - \\
\hline Uric acid (mg/dL) (3.5-7.2) & 1.57 & - & - & 2.2 & 0.43 & 0.82 & 0.94 & 1.55 \\
\hline Plasma osmolality (275-295) & - & - & - & - & - & - & 245 & - \\
\hline Renin pg/mL (2.7-16.5) & - & - & - & - & - & - & 5.56 & - \\
\hline Aldosterone (pg/mL) (10-160) & - & - & - & - & - & - & 142 & - \\
\hline TSH $\mu \mathrm{IU} / \mathrm{mL}(0.34-5.6)$ & - & - & $>100$ & - & $>100$ & - & $>100$ & 11 \\
\hline FT4 pmol/L (7.86-14.5) & - & - & 0.4 & - & 2.73 & - & 4.2 & 33.4 \\
\hline
\end{tabular}

$\mathrm{TSH}$, thyroid-stimulating hormone; FT4, free thyroxine. 


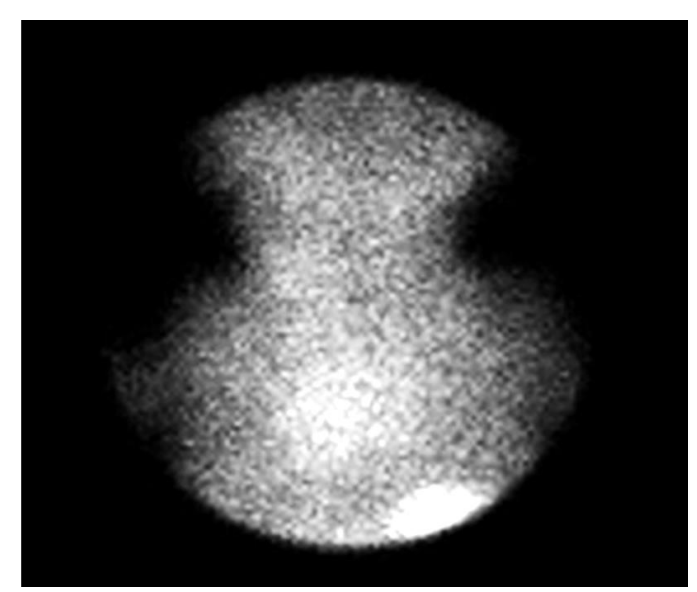

Fig. 2. Thyroid scan using ${ }^{99 m} \mathrm{Tc}$ revealed no radiotracer uptake suggested thyroid agenesis.

At the 11th day of hospitalization, while she was on oral fed with infant formula and receiving total parenteral nutrition with a maintenance sodium content $(40 \mathrm{mEq} / \mathrm{L})$, she developed poor feeding, vomiting, abdominal distention, and tachypnea. Laboratory investigations revealed severe hyponatremia (plasma sodium level was $106 \mathrm{mEq} / \mathrm{L})$ with normal potassium level (4.3 $\mathrm{mEq} / \mathrm{L})($ Fig. 1).

Infusion of hypertonic (3\%) saline $(1 \mathrm{~mL} / \mathrm{kg})$ and subsequent replacement of sodium deficit was commenced. At the 13th day of hospitalization plasma sodium level was $120 \mathrm{mEq} /$ $\mathrm{L}$ with inappropriately normal ranges renin and aldosterone levels (Table 2). Plasma osmolarity was $245 \mathrm{mOsm} / \mathrm{kg}$ and FT4 were still at hypothyroid level (Table 2). Eunatremia was achieved and can only remained stable with a 24-hour infusion of isotonic $(0.9 \%)$ sodium chloride. To attain the euthyroid state L-thyroxine dose was increased up to $100 \mu \mathrm{g} /$ day. After achievement of euthyroid state, serum sodium remained stable at the normal ranges without sodium replacement. Her L-thyroxine dose was tappered according to FT4 and TSH measurements and discharged with a maintanence dose of 37.5 $\mu \mathrm{g} /$ day. She is now 2.5 years old and on daily $37.5 \mu \mathrm{g}$ L-thyroxine therapy. In our recent contact with family through e-mail it was declared that she was not able to speak, walk and had severe mental and motor retardation.

\section{Discussion}

Herein, we report a case of $\mathrm{CH}$ due to thyroid agenesis who suffered from several complications due to delay in the diagnosis. Thyroid dysgenesis (aplasia, hypoplasia, or ectopia) is the most common cause of $\mathrm{CH}$, account for $80 \%-85 \%$ of cases ${ }^{7)}$. Our case had $\mathrm{CH}$ due to thyroid agenesis, confirmed by $99 \mathrm{~m} \mathrm{Tc}$ scan and correlative thyroid ultrasonography.

Majority of infants with $\mathrm{CH}$ can be asymptomatic or present with nonspecific signs and symptoms at birth. Therefore, in developing and underdeveloped countries where a neonatal screening programme is not available, delay in diagnosis may complicated with severe mental retardation. Although our case had developed 2 common symptoms of $\mathrm{CH}$, prolonged neonatal jaundice and intestinal dysmotility, diagnosis of $\mathrm{CH}$ was missed and resulted in severe mental retardation. Furthermore, she had undergone several unnecessary surgical operations and related complications.

Although there are few number of $\mathrm{CH}$ cases presented with intestinal dysmotility mimicking gastrointestinal system disorders $^{8}$, to the best of our knowledge, this is the first case underwent intestinal resections due to intestinal distention mimicking aganglionic megacolon in children with $\mathrm{CH}$. Hypothyroidism reduces intestinal motility, prolongs intestinal transit time thereby causes abdominal distention mimicking agonglionic megacolon. Our case had admitted at the age of 1 month with similar complaints and a misdiagnosis of aganglionic megacolon had been considered. Then several surgical resections preformed which resulted in short bowel syndrome. However, re-evaluation of parafin embeded blocks resected during previous surgeries revealed normal intestinal histology with presence of ganglionic neuronal cells.

The most common presenting findings in patients with delayed diagnosis of $\mathrm{CH}$ have been reported as growth failure (100\%) followed by developmental delay (73.5\%), coarse skin $(67.6 \%)$ and constipation $(64.7 \%)^{9)}$. In similar, at the time of admission to our clinic our case had severe growth retardation and developmental delay which was attributed to delayed diagnosis, chronic hospitalization, repeated surgical operations, short bowel syndrome and feeding difficulties. Other clinical findings were also in line with previous reports ${ }^{9}$. We, therefore, did not performed further metabolic investigations for the differential diagnosis of mental and motor retardation.

Our case had developed moderate hyponatremia at admission which was corrected easily, whilst, the symptoms had been aggrevated at the 11 th day of hospitalization, a week following commencement of thyroid hormone replacement. We could not found any report indicating relationship between development of hyponatremia and thyroid hormone replacement in the literature. However, she had developed hyponatremia at the time of admission and the most severe episode developed about a week following commencement of L-thyroxine. Besides, hypothyrodism per se is also known as a cause of hyponatremia and increased L-thyroxine dose for rapid correction of hypothyroidism improved hyponatremia in our case. Therefore, we did not atributed the L-tyhroxine therapy as a reason for hyponatremia of our patient. Moreover, as our case had short bowel syndrome due to repeated intestinal resections, malabsorption was suggested as potential underlying pathology for hyponatremia. On the other hand, since the severe episode of hyponatremia developed during respiratory distress, inappropriate secretion of ADH could be suggested to cause hyponatremia.

Thyroid hormones involve in the regulation of body fluid and sodium balance. However, the underlying mechanisms of hyponatremia in hypothyroidism have not been fully elucidated. In $\mathrm{CH}$ patients, one of the possible mechanism suggested to 
cause hyponatremia is impaired free water formation ${ }^{10)}$. Water loading test performed in patients with hypothyroidism, have shown failure to achieve maximum urine dilution, delayed formation of free water and reduced urine volume ${ }^{6}$. However, our patient had normal urine output.

Another mechanism has been suggested for hyponatremia in hypothyroidism is impaired osmoregulation or decreased metabolic clearence of $\mathrm{ADH}$ in hypothyroid state ${ }^{11)}$. In patients with severe hypothyroidism, high plasma ADH, lower osmotic threshold for ADH release have been reported ${ }^{12)}$. On the other hand, a low plasma ADH level with attenuated $\mathrm{ADH}$ response to the changes in plasma osmolality have also been reported in hypothyroidism ${ }^{6,13)}$. In some hypothyroid patients, hyponatremia had shown recovered by thyroid hormone replacement alone. Besides, these patients had normal or suppressed plasma ADH concentrations, thereby, it was suggested that water retention to be a direct effect of thyroid hormone deficiency on the renal tubules ${ }^{14)}$. In our case, we were not able to investigate plasma ADH level. However, our patient had developed respiratory distress which can lead inappropriate secretion of ADH. In addition (although was measured during saline infusion) the elevated urine sodium, low uric acid level, absence of hypervolemia was suggestive for secretion of inappropriate ADH. Besides, achieving eunatremia and maintenance of normal plasma sodium level after attaining euthyroidism was consistent with above reports.

The effects of thyroid dysfunction on the kidney include changes in renal blood flow, glomerular filtration rate, tubular functions, electrolyte pumps and kidney structure ${ }^{15,16)}$ Therefore, in hypothyroidism renal dysfunction may play role in the fluid and electrolyte imbalance. In a study evaluating renal functions of 15 patients with hypothyroidism before and after treatment, a significantly lower glomerular filtration rate and renal blood flow have been detected in hypothyroidism compared to euthyroid state ${ }^{17)}$. Thyroid hormones influence the postnatal renal $\mathrm{Na}-\mathrm{K}$-ATPase expression which drives active reabsorption of sodium. In $\mathrm{CH}$ renal $\mathrm{Na}-\mathrm{K}$-ATPase activity has been shown reduced in specific segments ${ }^{18)}$. Elevated urine $\mathrm{Na}$ in our case may suggest renal tubular dysfunction.

Another reported mechanism for hypothyroidism associated hyponatremia was reduction in ANP which exerts diuresis and natriuresis ${ }^{19)}$. In hypothyroidism, a low plasma ANP in association with reduced free water generation and recovery after thyroid hormone replacement has been reported ${ }^{6}$. We unfortunately, did not investigate the plasma ANP level in our case.

On the other hand thyroid hormones affect renin angiotensin-aldosterone system such as secretion of renin, production of hepatic angiotensinogen and expression of angiotensin II receptors ${ }^{20)}$. However, in their study Koide et al. ${ }^{14)}$ reported that neither vasopressin nor aldosterone plays a dominant role in the pathogenesis of the hyponatremia in patients with hypothyroidism. In our case, there was an inappropriately low response of renin and aldosterone secretion in course of natriuresis and hyponatremia. However, normal serum potassium level was excluded a clinically relevant mineralocorticoid deficiency.

In conclusion, present case report demonstrated the crucial role of neonatal screening for $\mathrm{CH}$ which provides prompt diagnosis and immediate treatment of $\mathrm{CH}$ patients. Besides, clinicians should be aware of the $\mathrm{CH}$ signs and symptoms and keep in mind $\mathrm{CH}$ in the differential diagnosis of patients presented with vomitting, abdominal distention and severe hyponatremia with unknown etiology in neonates and infants. Thyroid function tests might be included in the routine investigations of persistent intestinal dysmotility and hyponatremia of unknown origin, particularly in the pediatric population.

\section{Conflict of interest}

No potential conflict of interest relevant to this article was reported.

\section{References}

1. Rastogi MV, LaFranchi SH. Congenital hypothyroidism. Orphanet J Rare Dis 2010;5:17.

2. Chelimsky G, Davis ID, Kliegman RM. Neonatal hyponatremia associated with congenital hypothyroidism. Clin Pediatr (Phila) 1997;36:177-80.

3. Schutt-Aine JC. Hypothyroid myxedema and hyponatremia in an eight-year-old child: a case report. J Natl Med Assoc 1980;72:705-8.

4. Agathis NT, Libman IM, Moritz ML. Hyponatremia due to severe primary hypothyroidism in an infant. Front Pediatr 2015;3:96.

5. Hanna FW, Scanlon MF. Hyponatraemia, hypothyroidism, and role of arginine-vasopressin. Lancet 1997;350:755-6.

6. Ota K, Kimura T, Sakurada T, Shoji M, Inoue M, Sato K, et al. Effects of an acute water load on plasma ANP and AVP, and renal water handling in hypothyroidism: comparison of before and after L-thyroxine treatment. Endocr J 1994;41:99-105.

7. Brown RS, Demmer LA. The etiology of thyroid dysgenesisstill an enigma after all these years. J Clin Endocrinol Metab 2002;87:4069-71.

8. Korkmaz L, Akın MA, Güneş T, Daar G, Baştuğ O, Yıkılmaz A, et al. Unusual course of congenital hypothyroidism and route of the L-thyroxine treatment in a preterm newborn. J Clin Res Pediatr Endocrinol 2014;6:177-9.

9. Seth A, Aggarwal V, Maheshwari A. Hypothyroidism in children beyond $5 \mathrm{y}$ of age: delayed diagnosis of congenital hypothyroidism. Indian J Pediatr 2012;79:891-5.

10. Skowsky WR, Kikuchi TA. The role of vasopressin in the impaired water excretion of myxedema. Am J Med 1978;64:613-21.

11. Kimura T. Potential mechanisms of hypothyroidisminduced hyponatremia. Intern Med 2000;39:1002-3. 
12. Laczi F, Janáky T, Iványi T, Julesz J, László FA. Osmoregulation of arginine-8-vasopressin secretion in primary hypothyroidism and in Addison's disease. Acta Endocrinol (Copenh) 1987;114:389-95.

13. Iwasaki Y, Oiso Y, Yamauchi K, Takatsuki K, Kondo K, Hasegawa $\mathrm{H}$, et al. Osmoregulation of plasma vasopressin in myxedema. J Clin Endocrinol Metab 1990;70:534-9.

14. Koide Y, Oda K, Shimizu K, Shimizu A, Nabeshima I, Kimura S, et al. Hyponatremia without inappropriate secretion of vasopressin in a case of myxedema coma. Endocrinol Jpn 1982;29:363-8.

15. Park CW, Shin YS, Ahn SJ, Kim SY, Choi EJ, Chang YS, et al. Thyroxine treatment induces upregulation of reninangiotensin-aldosterone system due to decreasing effective plasma volume in patients with primary myxoedema. Nephrol Dial Transplant 2001;16:1799-806.

16. Munro DS, Renschler H, Wilson GM. Exchangeable potassium and sodium in hyperthyroidism and hypothy- roidism. Metabolism 1958;7:124-32.

17. Villabona C, Sahun M, Roca M, Mora J, Gómez N, Gómez $\mathrm{JM}$, et al. Blood volumes and renal function in overt and subclinical primary hypothyroidism. Am J Med Sci 1999;318:277-80.

18. Nakhoul F, Thompson CB, McDonough AA. Developmental change in $\mathrm{Na}, \mathrm{K}$-ATPase alphal and betal expression in normal and hypothyroid rat renal cortex. Am J Nephrol 2000;20:225-31.

19. Kohno M, Takaori K, Matsuura T, Murakawa K, Kanayama Y, Takeda T. Atrial natriuretic polypeptide in atria and plasma in experimental hyperthyroidism and hypothyroidism. Biochem Biophys Res Commun 1986; 134:178-83.

20. Ruiz M, Montiel M, Jimenez E, Morell M. Effect of thyroid hormones on angiotensinogen production in the rat in vivo and in vitro. J Endocrinol 1987;115:311-5. 